
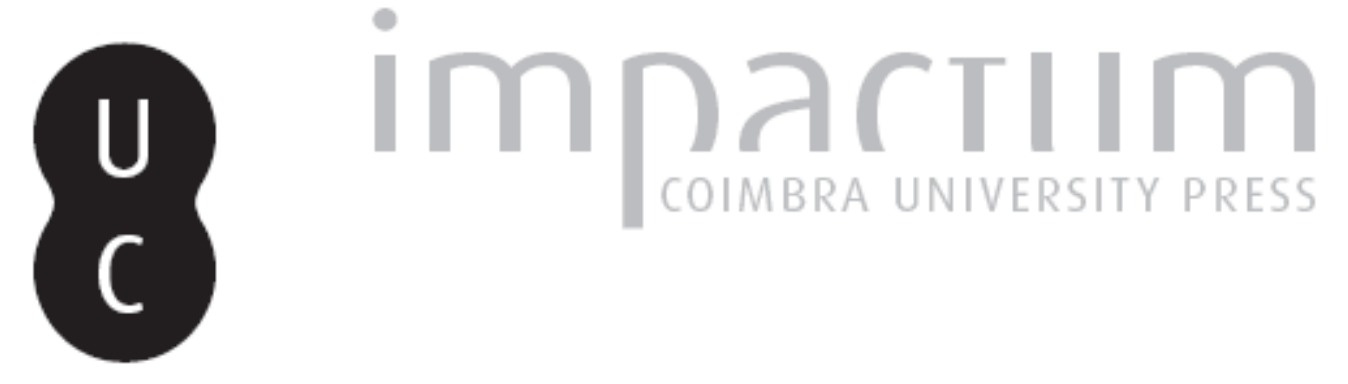

\title{
Urbanização e riscos ambientais, na cidade de Salvador - Bahia
}

Autor(es): $\quad$ Santos, Miguel Cerqueira dos

Publicado por: Associação Portuguesa de Riscos, Prevenção e Segurança

URL persistente:

URI:http://hdl.handle.net/10316.2/36060

DOI:

DOI:http://dx.doi.org/10.14195/1647-7723_18_17

Accessed : $\quad$ 26-Apr-2023 09:28:18

A navegação consulta e descarregamento dos títulos inseridos nas Bibliotecas Digitais UC Digitalis, UC Pombalina e UC Impactum, pressupõem a aceitação plena e sem reservas dos Termos e Condições de Uso destas Bibliotecas Digitais, disponíveis em https://digitalis.uc.pt/pt-pt/termos.

Conforme exposto nos referidos Termos e Condições de Uso, o descarregamento de títulos de acesso restrito requer uma licença válida de autorização devendo o utilizador aceder ao(s) documento(s) a partir de um endereço de IP da instituição detentora da supramencionada licença.

Ao utilizador é apenas permitido o descarregamento para uso pessoal, pelo que o emprego do(s) título(s) descarregado(s) para outro fim, designadamente comercial, carece de autorização do respetivo autor ou editor da obra.

Na medida em que todas as obras da UC Digitalis se encontram protegidas pelo Código do Direito de Autor e Direitos Conexos e demais legislação aplicável, toda a cópia, parcial ou total, deste documento, nos casos em que é legalmente admitida, deverá conter ou fazer-se acompanhar por este aviso.

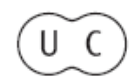




\section{territorium}

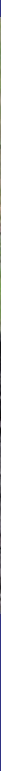

\section{Afirmar as Ciências Cindínicas}

Revista da Associação Portuguesa de Riscos, Prevenção e Segurança 
Miguel Cerqueira dos Santos

Professor Doutor da Universidade do Estado da Bahia - UNEB migcerq@yahoo.com.br

\section{RESUMO}

O uso e ocupação do solo de Salvador tem provocado sérios problemas. Este trabalho analisa as principais causas e consequências dos riscos ambientais, decorrentes do processo de urbanização. A metodologia adotada teve como pontos básicos a leitura de autores clássicos e contemporâneos e a realização de trabalho de campo. Salvador é predominantemente composta por morros, que apresentam semelhanças geomorfológicas, mas potencializam riscos ambientais diferenciados, a depender das condições socioeconômicas e culturais da população que ocupa essas áreas. Palavras-chave: Urbanização, riscos ambientais, qualidade de vida.

\section{RESUMEN}

El uso y ocupación de la ciudad de Salvador ha causado problemas graves. Este artículo examina las principales causas y consecuencias de los riesgos ambientales derivados del proceso de urbanización. la metodología utilizada tiene como base la lectura de autores clásicos y contemporáneos y lla realización del trabajo de campo. Salvador está predominantemente compuesta de colinas, que presentan semejanzas geomorfológicas, pero potencian diferentes riesgos ambientales, dependiendo de las condiciones socioeconómicas y culturales de la población que ocupa estas áreas.

Palabras clave: La urbanización, los riesgos ambientales, calidad de vida.

\section{RÉSUMÉ}

Le type d'utilisation et l'occupation du Salvador a causé de graves problèmes. Ce document analyse les principales causes et les conséquences des risques environnementaux découlant du processus de l'urbanisation. La méthodologie adoptée a été la base de la lecture d'auteurs classiques et contemporains et de travail sur le terrain. La ville de Salvador est principalement composé de collines, qui ont été géomorphologiques semblables, mais de potentialiser les différents risques, en fonction des conditions socio-économiques et culturels de la population occupe ces zones. Mots-clés: Urbanisation, les risques environnementaux, la qualité de vie.

\section{ABSTRACT}

The type of use and occupation of Salvador has caused serious problems. This paper analyzes the main causes and consequences of environmental risks arising from the urbanization process. The methodology adopted was the basics of reading classical and contemporary authors and conducting fieldwork. The city of Salvador is predominantly composed of hills, which were similar geomorphological, but potentiate different risks, depending on the socioeconomic and cultural conditions of the population occupies these areas.

Keywords: Urbanization, environmental risks, quality of life.

* O texto deste artigo corresponde à comunicação apresentada ao II Congresso Internacional de Riscos e VI Encontro Nacional, tendo sido submetido para revisão em 14-07-2010, tendo sido aceite para publicação em 15-10-2010.

Este artigo é parte integrante da Revista Territorium, n. ${ }^{\circ} 18,2011$, ${ }^{\circledR}$ RIsCOS, ISBN: 0872- 8941. 


\section{Introdução}

O processo de urbanização ocorrido na cidade de Salvador tem a ver com o ritmo de crescimento adotado pela maioria das cidades brasileira, mas também evidencia algumas particularidades que merecem ser estudadas. A ideia de crescimento urbano calcada na concepção de pólo de crscimento, com a formação de um centro polarizador, em detrimento de uma periferia cada vez mais dependente, trouxe sérias consequências para as condições de vida da maioria da população soteropolitana. A análise do modelo de crescimento com o isolamento entre as interferências humanas e as condições físicas contidas neste território dificulta a compreensão dos riscos ambientais encontrados na cidade de Salvador.

A investigação calcada nas relações físicoculturais, contidas no processo de urbanização, possibilita a compreensão dos problemas urbanos evidenciados atuamente, como respostas aos descasos no planejamento de sucessivas épocas, de modo a prevenir dos prejuízos que poderão ser gerados para um futuro bem mais próximo do que se possa imaginar. A forma como a morfologia urbana da cidade em questão foi configurada, ao longo do crescimento populacional, contribuiu para a potencialização de riscos que podem tornar cada vez mais vulneráveis ao desencadeamento de efeitos calamitosos.

O objetivo deste trabalho é analisar as principais causas e consequências dos riscos ambientais, decorrentes do processo de urbanização ocorrido nesta cidade. A metodologia adotada neste estudo foi constituída a partir da análise diversificada de informações que resultaram na formação deste texto. A leitura de autores clássicos e contemporâneos, o levantamento de dados junto às instituições públicas, principalmente da Prefeitura Municipal, através da Defesa Civil de Salvador - CODESAL, além das observações in loco, seguida de diálogos com as populações que habitam as áreas de riscos, constituem alguns dos exemplos.

A cidade de Salvador iniciou as primeiras ocupações calcadas em interesses políticos, econômicos e religiosos, que resultaram na definição do sítio urbano. A escolha de uma área protegida por uma baia, localizada em uma falha geológica, dividindo a cidade em alta e baixa, próxima a inúmeros canais que desaguavam na Baía de Todos os Santos motivou o assentamento dos primeiros aglomerados. O surgimento das atividades terciárias, na parte baixa, onde se encontra atualmente o centro comercial e financeiro, e a concentração das relações de poder político, econômico e religioso, na parte alta, área de atual atração turística, atendia aos interesses da época. A presença de áreas verdes, a preservação dos rios e canais e a regulação natural da infiltração e do escoamento superficial e subsuperficial garantiam o equilíbrio entre as relações físicoculturais, contidas nesse território.

Entretanto, a investigação revela o acúmulo de dificuldades que a cidade de Salvador passou a produzir, principalmente no período posterior à década de 1950 . Uma das questões que merecem destaque refere-se ao fato de que a configuração urbana é predominantemente composta por morros e colinas, que em alguns casos têm formações edafoclimáticas semelhantes, mas traduzem-se em riscos ambientais diferenciados, a depender das condições socioeconômicas e culturais da população que ocupa essas áreas. Estas questões estão no cerne das discussões que buscam alternativas para o desenvolvimento da urbanização, com melhoria da qualidade ambiental e, consequentemente, condições de vida para os habitantes da cidade de Salvador.

\section{A concepção de riscos}

A concepção de riscos aqui estudadas tem a ver com a evolução deste conceito ocorrida nos últimos anos. A ideia de riscos sempre esteve atrelada ao perigo que determinados acontecimentos provocam para a humanidade. Inicialmente esta situação era mais evidenciada a partir dos riscos naturais, onde havia pouca atenção aos problemas relacionados com as intervenções humanas. No transcorrer dos tempos, os estudos de riscos passaram a assumir uma dimensão mais alargada, inclusive passando a ser analisada numa perspectiva social (BECK, 1992). O fato de a causa de inúmeros riscos estar diretamente relacionada com os fenômenos naturais, a exemplo de maremotos, terremotos e vulcões, não significa dizer que a sua preocupação esteja alheia às ações antrópicas (Rebeto, 2003).

As discussões sobre riscos têm demandado várias questões relacionadas com as diferentes mutações territoriais envolvendo natureza e sociedade. A cada dia há evidência de riscos nas diferentes escalas de abordagem, o que demanda a existência de estudos multidisciplinares. A aproximação com estudos de riscos exige uma análise cuidadosa, não somente dos impactos provocados à sociedade, mas principalmente do processo que resulta na consequente degradação ambiental. A partir do momento em que determinados fenômenos provocam perigos para a sociedade, podendo ser a causa natural ou antrópica, ocorrem os riscos ou azares (GonçAlves, 2003). Daí a existência de uma complexidade de fatores que poderão estar provocando ou não riscos ambientais. Há um conjunto de elementos que podem variar desde a ocorrência de eventos ditos naturais como terremotos, vulcanismos e enchentes, até as ações de orígem antrópica como a violência urbana, o terrorismo e os acidentes de trânsito, dentre outros. Além disso, 
convém lembrar que no processo de entendimento dos riscos, as dimensões culturais são imprescindíveis. Isso porque a magnitude dessas ocorrências varia desde os aspectos físicos até os relacionados com os diferentes modos de vida, aos quais também se inserem os fatores de ordem comportamental e psicológica.

Diante da complexidade envolvida com os diferentes tipos de riscos encontrados na contemporaneidade, demanda cada vez mais a necessidade de direcionar o tipo de riscos que se pretende estudar. Nesse caso, foram escolhidos aqueles relacionados com o tipo de uso e ocupação do solo da cidade de Salvador. As áreas de encostas constituem a maior parte do padrão de urbanização da área estudada e apresentam o maior número de acontecimentos envolvendo deslizamentos e desmoronamentos, principalmente nos bairros de populações pobres.

\section{Urbanização de Salvador}

O processo de urbanização de Salvador tem início nas primeiras ocupações territoriais brasileiras, no século XVI, quando o Brasil, na condição de colônia portuguesa, praticamente nasceu urbano. A fundação da cidade de Salvador, em 29 de março de 1549, surge como respostas às funções relacionadas com os interesses político-administrativos, de segurança, comerciais e de serviços. $\mathrm{Na}$ análise dos riscos ambientais, decorrentes da urbanização na cidade de Salvador, não convém se estender ao processo de urbanização ocorrido desde a colonização portuguesa até os dias atuais. Isso porque o foco desta discussão provém da relacão entre o modelo de crescimento urbano e os riscos ambienatais encontrados, sobretudo após a década de 1950.

Os períodos anteriores foram importantes para o entendimento das questões atuais, mas isso será feito por um breve comentário. A cidade de Salvador surge da intensa correlação entre os interesses dos portugueses, no tocante à escolha de um lugar protegido e potencialmente importante para a expansão das atividades comerciais e de serviços. A sua localização geográfica, às portas de entrada da Baía de Todos os Santos, foi de fundamental importância para a escolha do sítio urbano. A cidade de Salvador iniciou o seu processo de ocupação no graben da falha, nas áreas de planícies, de frente para um conjunto de cidades que forneciam os produtos primários: cana-de-açucar, fumo, milho, feijão, voltados para o abastecimento da metrópole, no caso Portugal. A ligação com importantes rios que deságuam na Baía de Todos os Santos, a exemplo do Paraguaçu, Jaguaripe e Da Dona, proporcionou a formação de uma hinterland composta por cidades importantes que constituíram a primeira rede urbana do Recôncavo, a exemplo de Cachoeira, São Félix, Nazaré e Maragogipe (fig. 01).

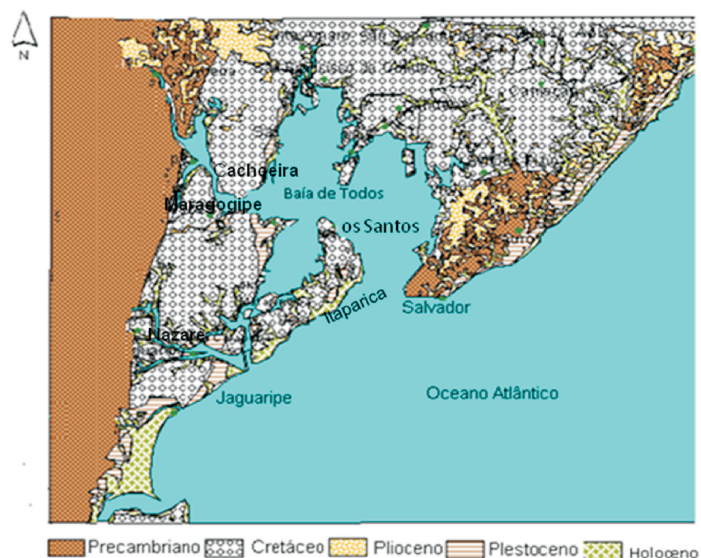

Fig. 1 - Baía de Todos os Santos.

Fonte: Elaborado por Miguel SANTOS, com base na Secretaria das Minas e Energia, 1980.

Os centros urbanos localizados ao entorno da Baía de Todos os Santos tinham como ponto principal de convergência a cidade de Salvador, que foi a primeira capital do Brasil, por 214 anos, entre 1549 a 1763, quando houve a transferência para o Rio de Janeiro. Desde os princípios da colonização, em que o sítio urbano de Salvador foi sendo ocupado de maneira significativa, até a sua intensificação ocorrida na década de 1950, com o advento da industrialização. A transferência da capital do Brasil para o Rio de Janeiro, no final do século XVIII, teve como uma das principais causas a segurança territorial (Matoso, 1992). Mesmo assim, a cidade de Salvador continuou o seu ritmo de crescimento, pois exercia importante papel na Rede Urbana do Recôncavo, principalmente no tocante à administração e distribuição da produção oriunda das demais cidades do Estado.

As mudanças ocorridas entre o final do século XIX e início do século XX foram importantes para a reconfiguração do desenho urbano de Salvador, sobretudo em decorrência da transição entre o modelo escravista e a inserção do novo ritmo de crescimento das atividades comerciais e de serviços. O tipo de ocupação que predominava até esta época era resultado de uma conjugação entre os prédios construídos para o comércio, na parte térrea, e para a habitação dos proprietários, no pavimento superior. Enquanto isso, na parte do horst, onde atualmente se localiza o Centro Histórico, havia uma muralha, utilizada no período colonial, como forma de proteção. Existiam duas portas principais: uma ao norte, na Ladeira do Carmo, e a outra ao Sul, no Largo do São Bento. A partir do século XIX, mediante um contexto de industrialização por que passava o mundo europeu, houve o processo de derrubada das muralhas, para serem substituídas por outras formas de proteção, a exemplo das armas resultantes da nova tecnficação territorial (LAmAs, 2000).

O entendimento dos inúmeros riscos ambientais encontrados atualmente na cidade de Salvador, 
principalmente no tocante à forma como a população pobre acessa os seus locais de moradias, assentando-se de forma inadequada nas encostas, advém de sucessivas segregações espaciais, oriundas de longas datas. No início do século XX, após a derrubada das muralhas, houve novas tendências da ocupação urbana. A população mais abastada abdicou do estilo de residência, no mesmo prédio de funcionamento do comércio, e passou a habitar em sobrados situados na parte plana e alta do centro histórico de Salvador, sobretudo onde atualmente está localizado o Pelourinho. Os proprietários do comércio, compostos por portugueses e seus descendentes diretos, na maioria, habitaram por várias décadas esta localidade (ANDRADE, 2004) Enquanto isso, a população pobre, predominantemente composta por negros, despojados do processo de escravidão, ocupava a porção norte da cidade, em direção as áreas constituídas atualmente pelos bairros da Liberdade, Ribeira e o subúrbio ferroviário, ou habitavam as áreas, de menor valor, na parte sul, nas proximidades do Campo Grande, onde está localizada a Gamboa.

Até a década de 1950, o crescimento urbano de Salvador já anunciava problemas ambientais, decorrentes da forma de acesso à renda e à moradia. Sem dúvidas, a relação entre o físico e o cultural acontecia de maneira mais equilibrada, visto que os impactos causados pela forma de uso e ocupação do solo eram menores, em decorrência do ritmo de crescimento da população. As mudanças mais estruturais na reconfiguração do espaço urbano de Salvador aconteceram dos meados do século XX até o seu final. Estas mutações territoriais não aconteceram de forma dissociada do contexto em que o território brasileiro começou a experimentar a partir dessa época. A década de 1950 foi um marco importante para a consolidação do modelo de urbanização atualmente encontrado.

O processo de industrialização iniciado mais cedo, na região sul, e intensificado no Estado da Bahia, principalmente com a implantação da Petrobras e posterior instalação do CIA (Centro Industrial de Aratu) e do COPEC (Complexo Petroquímico de Camaçari) contribuiu para elevar o ritmo de crescimento da rede urbana do Recôncavo. A implantação das redes viárias, em detrimento dos transportes de cabotagem e ferroviários, aliada à falta de política de fixação dos trabalhadores rurais, que foram atraídos pela pseudo ideia de desenvolvimento, gerada pelo crescimento industrial e pelas atividades comerciais e de serviços, evidenciou os contrastes no tipo de uso e ocupação do solo. As áreas de encostas, as reservas ecológicas e os sobrados que foram abandonados, anteriormente, pela população mais abastada passaram a ser intensamente ocupados pela população pobre, sem as mínimas infraestruturas.
A abertura das avenidas de vale e as facilidades de concessão de terras aos especuladores imobiliários colocararm Salvador diante de uma forte dicotomia: por um lado, inibiu a população menos abastada do acesso aos bens e serviço e à moradia digna. Por outro lado, possibilitou o crescimento das construções das classes médias e altas, em áreas de preservação ambiental e nos terrenos dotados de melhores infraestruturas. No período posterior à década de 1950, Salvador recebe intenso contingente populacional, oriundo das áreas agrícolas que perderam o dinamismo evidenciado desde o processo colonial, principalmente com o cultivo da cana, do fumo e dos produtos de subsistências. 0 aumento das redes de transportes e comunicação, engendrado pela influência da industrialização e do crescimento das atividades terciárias, favoreceu a mobilidade populacional que passou a ocupar as áreas de riscos na cidade de Salvador.

As encostas, as escarpa de falhas e os terrenos alagados, localizados nas áreas de preamar, em bairros como Uruguai, Massaranduba e Jardim Cruzeiro, passaram a ser intensamente ocupadas. Salvador começa a definir dois corredores básicos de ocupação territorial, com forte desigualdades sociais: o da orla atlântica, ocupado pela população de melhor poder aquisitivo e o da orla da Baía de Todos os Santos, habitado pela maioria da população pobre (fig. 2).

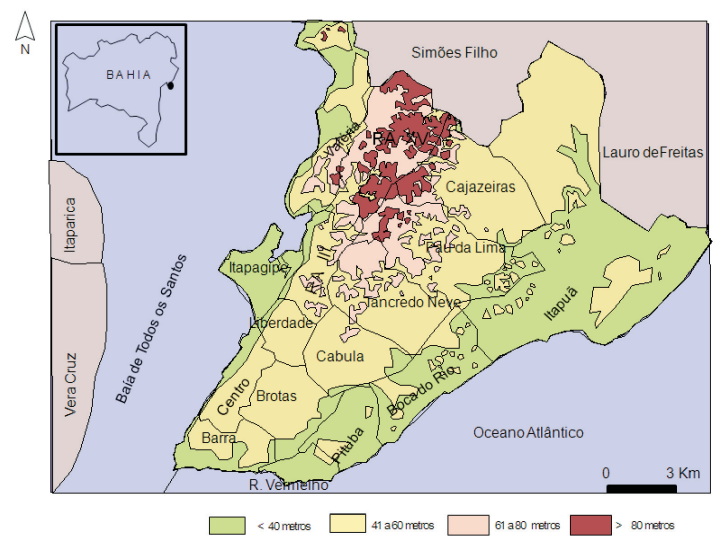

Fig. 2 - Regiões administrativas de Salvador. Fonte: Elaborado por Miguel SANTOS, com base na Prefeitura Municipal de Salvador, 2003.

A figura 2 evidencia as regiões administrativas de Salvador, com as respectivas altimetrias representadas na forma de relevo. Nota-se que na Orla Atlântica estão situadas as áreas mais suaves, com extensa planíce costeira, o que proporciounou maior valorização do solo urbano. Em função disso, há uma apropriação por parte da população dotada de melhor poder aquisitivo, com o consequente acompanhamento das obras de infraestrutura. Enquanto isso, a figura 2 também demonstra a área situada no graben da falha, na parte oeste de Salvador, na orla da Baía de Todos os Santos. Nesta porção territorial, ocorre 
a concentração da população pobre, oriunda das áreas rurais, atraída pela pseudo ideia de desenvolvimento, engendrada com o crescimento da indústria na Bahia.

A intensificação do processo de urbanização, ocorrida nas últimas décadas, colocou Salvador entre as três capitais com maior contingente populacional do país. Em contrapartida, não possibilitou comparáveis avanços nas condições de acesso à saúde, à educação de qualidade e à habitação digna para a maioria da população. O modelo de crecimento urbano na Bahia sempre esteve voltado para uma enorme concentração na área metropolitana, sobretudo na cidade de Salvador (QUADRO I).

$\mathrm{Na}$ relação dos 12 municípios com mais de $100 \mathrm{mil}$ habitantes no Estado da Bahia, observa-se que Salvador apresenta um número cinco vezes maior do que o segundo mais populoso da Bahia, no caso Feira de Santana, e representa $18,6 \%$ do total da população encontrada nos 417 municípios que compõem o Estado. Nota-se, também, que o município de Salvador praticamente não dispõe de área rural, em função do seu rápido processo de urbanização experimentado após o ano de 1950. Estes desajustes acumulados ao longo do período de crescimento urbano, sem as devidas políticas públicas de inserção da população pobre, tem contribuído para o aumento de vários problemas ambientais. Há riscos de violência, há sérios problemas de congestionamento do trânsito, em decorrência da falta de opção de transportes públicos com maior eficiência, a exemplo do Metrô que se arrasta por muitos anos e ainda não foi concluído. Entretanto, os riscos ambientais que estão sendo enfatizados neste artigo referem-se a aqueles relacionados com os deslizamentos e desmoronamentos decorrentes da ocupação inadequada da população pobre, que avança pelas encostas da cidade de Salvador.

\section{Os riscos ambientais}

O modelo de urbanização ocorrido na cidade de Salvador proporcionou sérios contrastes, conforme explicado anteriormente. Os riscos analisados apresentam forte relação com a maneira pela qual as intervenções humanas foram sucessivamente ocorrendo no território estudado. A configuração urbana da referida cidade, contendo mares de morro, encostas íngremes, com solos suceptíveis a deslizamentos e desmoronamentos e portadora de um regime de chuva tropical, com maior concentração no outono e inverno, não determina, mas influencia na ocorrência dos riscos. Não resta dúvida de que as relações entre o físico e o cultural em alguns momentos potencializam e em outros podem minimizar os riscos ambientais. Daí convém refletir que:

"a cidade que ora nos desafia é uma complexa mistura (ou combinação?) de natureza e cultura numa caprichosa combinação de uma ordem simbólica, a partir de uma humanização do espaço e do tempo. Espaço cenário que nos abrigue e nos proteja na dinâmica de nossa movimentação quotidiana num tempo cada vez mais precioso" (MONTEIRO, 2008: 131).

Diante da argumentação exposta pelo autor, vale ressaltar que as relações entre natureza e sociedade precisam estar presente nos diferentes estudos territoriais. No caso da análise de risco na cidade de Salvador, onde a ocupação da maioria da população se estende pelas áreas de encosta, a análise dos riscos calcados nas relações físicoculturais torna-se indispensável. A forma como a população pobre exerce suas práticas quotidianas e ocupa os espaços rejeitados pela população de melhor poder aquisitivo, foi uma das principais razões discutidas neste estudo. A escolha do sítio urbano de Salvador, numa

QUADRO I - Municípios acima de 100 mil habitantes no Estado da Bahia.

\begin{tabular}{|c|c|c|c|c|}
\hline Município & Região & População & $\begin{array}{l}\text { Participação } \\
\text { no Estado (\%) }\end{array}$ & $\begin{array}{c}\text { Tx. de } \\
\text { Urbanização } \\
\text { (\%) }\end{array}$ \\
\hline Salvador & Metropolitana & 2.443 .107 & 18,68 & 99,96 \\
\hline Feira de Santana & Paraguaçu & 480.949 & 3,68 & 89,77 \\
\hline Vitória da Conquista & Sudoeste & 262.494 & 2,01 & 85,92 \\
\hline Ithéus & Litoral Sul & 222.127 & 1,70 & 72,99 \\
\hline Itabuna & Litoral Sul & 196.675 & 1,50 & 97,21 \\
\hline Juazeiro & B.Médio S.Francisco & 174.567 & 1,33 & 76,28 \\
\hline Camaçari & Metropolitana & 161.727 & 1,23 & 95,47 \\
\hline Jequié & Sudoeste & 147.202 & 1,13 & 88,52 \\
\hline Barreira & Oeste & 131.849 & 1,00 & 87,82 \\
\hline Alagoinhas & Litoral Norte & 130.095 & 0,99 & 86,43 \\
\hline Lauro de Freitas & Metropolitana & 113.543 & 0,87 & 95,46 \\
\hline Teixeira de Freitas & Extremo Sul & 107.486 & 0,82 & 91,81 \\
\hline Total & & 4.571 .821 & 34,94 & 88,97 \\
\hline
\end{tabular}

Fonte: Elaborado por Miguel SANTOS, com base no IBGE, 2000. 
área rodeada por morros e colinas, com abundância da água, do verde e margeada pela Baía de Todos os Santos, constituiu um Porto Seguro para uns, mas gerou sérios problemas para outros.

Os riscos que estão sendo estudados provêm da maneira como a relação físicocultural passou a ser evidenciada pela população pobre, principalmente com a intensificação do processo de urbanização de Salvador, ocorrido após a década de 1950. As constantes obras de terraplanagem efetuadas para a construção da cidade, sem as devidas precauções, aliada à carência de condições socioeconômica da população excluída dos bens e serviços de qualidade potencializaram riscos de vida (fot.1).

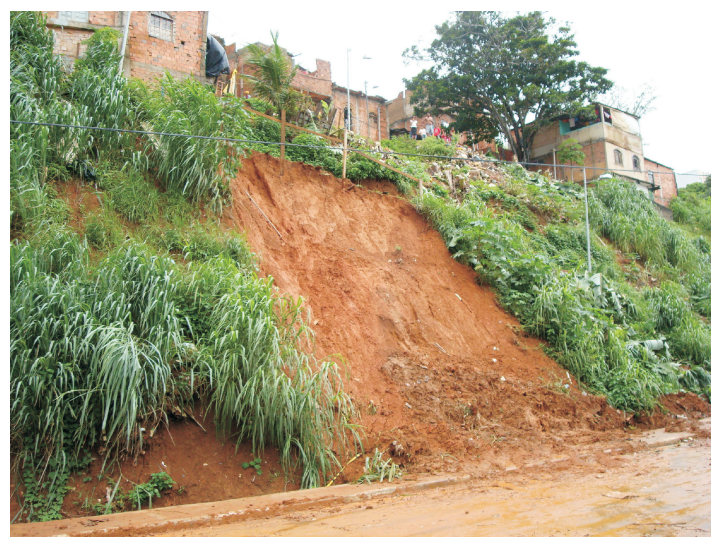

Fot.1 - Área de risco na cidade de Salvador.

Fonte: Prefeitura Municipal de Salvador - CODESAL, 2009.

No levantamento realizado na cidade de Salvador, foram registrados 100 mil pessoas, nas 2170 áreas de riscos, em 553 encostas (CODESAL, 2009). A foto 1 demonstra os perigos que a população de menor poder aquisitivo se expõe durante o quotidiano. As encostas com elevadas inclinações, que numa situação de planejamento urbano deveriam ser preservadas, acabam por ser a única opção de moradia para essas pessoas. Além da ocupação de áreas com alto grau de riscos de deslizamento, ou até mesmo de desmoronamento, acabam por plantar bananeiras, coco e outras frutas que concorrem para uma relação de conflitos entre o físico e o cultural, intensificando o perigo. A outra causa identificada como potencializadora dos riscos ambientais estudados, refere-se à coleta e deposição inadequada dos resíduos sólidos e líquidos. A situação de descaso dos poderes públicos, a dificuldade de acesso ao saneamento pela maioria das habitações, aliados à carência de uma trabalho educativo potencializam os riscos encontrados.

A maioria dos riscos estudados na cidade de Salvador está relacionado com os maus procedimentos decorrentes do modelo de urbanização implantado. A carência de canalização da rede de esgoto e a deposição de lixo a ceu aberto, por exemplo, contribuem para a desestabilização da maioria do tipo de solo, que por sua natureza já tem pouca estabilidade. 0 elevado número de ocupações, predominantemente da população pobre, nas nas áreas de encostas, em terrenos instáveis, sem a aquisição de equipamentos técnicos para o embasamento arquitetônico, reforça a ocorrência de riscos ambientais. A maioria dos solos encontrados nas áreas de riscos decorre do quaternário, localizados em áreas de escarpa de falha, com intenso teor de argila e silto, dotado de pouca espessura, o que concorre para a incidência de deslizamentos, principalmente nos períodos de maior concentração das chuvas.

A relação dos índices pluviométricos com a ocorrência de riscos ambientais na cidade de Salvador constitui uma abordagem interessante para a busca de alternativas para esta problemática (GonçAlves, 2003). Numa cidade de clima tropical, localizada entre as latitudes de $12^{\circ} \mathrm{e}$ $73^{\prime}$ a $13^{\circ}$ e $01^{\prime}$ Sul e as Longitudes de $38^{\circ}$ e $70^{\prime}$ a $38^{\circ}$ e $30^{\prime} \mathrm{W}$, as variáveis climáticas envolvendo temperatura, umidade do ar e ventos são importantes, para o conjunto da dinâmica que está associada com a ocorrência dos riscos ambientais. Diante dessas preocupações, foi feito um cruzamento de dados envolvendo os índices pluviométricos e a ocorrência dos riscos na cidade de Salvador (fig. 3).

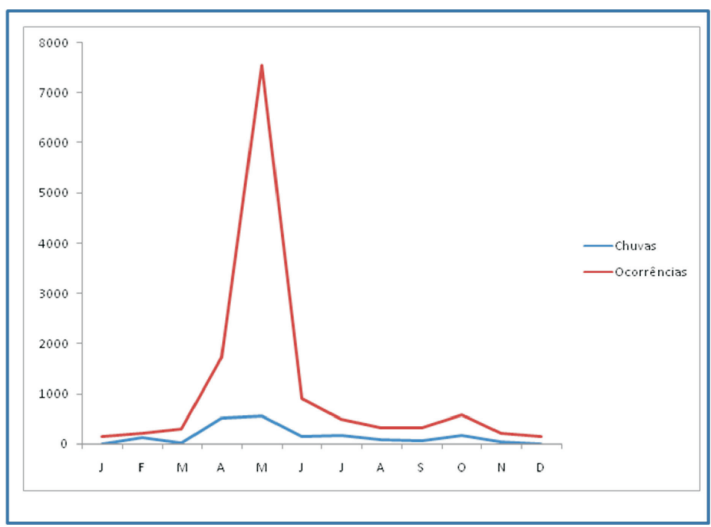

Fig. 3 - Pluviosidade e riscos em Salvador. Fonte: Miguel SANTOS, com base na CODESAL, 2009.

A figura 3 evidencia a intensa correlação existente entre os índices de pluviosidade e os riscos ambientais, na cidade de Salvador. Aliado a isso, a concentração dos índices pluviomémtrico em determinados período do ano tem provocado impactos, tanto no aspecto material, a exemplo dos deslizamentos, desmoronamentos, enchentes, como também para no imaterial. Isso porque a representação e o significado das chuvas para as pessoas que habitam as áreas de riscos, na cidade de Salvador, são diferentes daqueles que residem nas comunidades rurais ou até mesmo nos bairros dotados de melhor infraestrutura. As incidências dos deslizamentos e desmoronamentos ocorridos nos meses de abril, maio 
e junho, justamente no maior período de ocorrência das chuvas têm se constituído num verdadeiro desafio para a população e os demais envolvidos com esta problemática. Vale ressaltar que apesar deste período ser o mais intenso, há também um número de ocorrência significativa nos meses de outubro novembro e dezembro, com chuvas de primavera e verão. Isso demanda maior preocupação por parte dos profissionais envolvidos com esta questão. O mapeamento das áreas de riscos constituem uma das ações importantes para a busca de alternativas visando melhorar as condições de vida da população soteropolitana e a paisagem ambiental para quem visita Salvador. A opção pela diferença de amplitudes, no caso baixo, médio e alto, torna mais claro onde o fenômeno ocorre e com que dimensão. Observase o quanto a configuração física está correlacionada com a incidência de riscos na cidade de Salvador. Ao ser analisado de leste para oeste, verifica-se a mudança na intensidade e qualidade dos riscos analisados.(fig. 4).

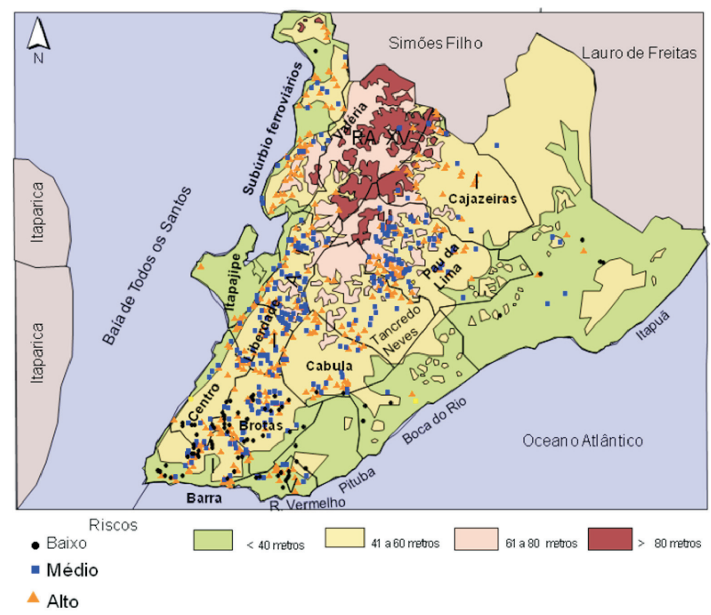

Fig. 4 - Riscos ambientais na cidade de Salvador. Fonte: Elaborado por Miguel SANTOS, com base na Prefeitura Municipal de Salvador, 2003.

A figura 4 oferece melhor ideia de como as áreas de riscos estão distribuídas no espaço urbano de Salvador. À medida em que ocorre o afastamento das áreas de planícies, localizadas na Orla Atlântica, aumenta a concentração dos riscos, tanto para Norte quanto para o Oeste, porém com maior incidência nas áreas de altitudes mais elevadas, portadoras de solos mais instáveis e habitada pela população pobre. A análise do processo de urbanização da cidade de Salvador, correlacionada com a incidência dos riscos ambientais ajuda a entender como as relações territoriais são constituídas em função dos dois circuitos da economia (SAntos, 1979). Por um lado, o circuito superior, constituído pela população de classe média e alta, em sua maioria, localizada nas áreas de melhor infraestrutura. Por outro, o circuito inferior encontra-se predominantemente constituído pela população pobre, com baixo poder aquisitivo e dotada das maiores dificuldades de acesso à renda, à saúde, à educação de qualidade e ao lazer. Vale frisar que no caso do modelo de urbanização encontrado na cidade de Salvador isso não acontece com uma tessitura tão linear. Tanto nas áreas consideradas centrais como periféricas, há ocorrências de populações pobres ao entorno de uma classe de poder aquisitivo médio e alto. 0 que difere são as condições de uso e ocupação dessas áreas, pelos diferentes estatutos da sociedade. O aumento dos descasos no tipo de uso e ocupação do solo, com forte desmatamento de áreas que poderiam ser protegidas e com o aterramento de inúmeros canais pluviais, tem intensificado a situação de riscos. 0 impacto provocado pela dificuldade de equilíbrio entre o físico e o cultural tem sido cada vez mais evidente nas diferentes dimensões espaciais da cidade de Salvador. Dificilmente, ricos, pobres e visitantes desta cidade não se deparam com uma situação constrangedoras nos períodos mais chuvosos. Há sempre uma situação de risco, seja por deslizmento de terras, desmoronamento ou alagamento de vias.

\section{Considerações}

A maneira como o processo de urbanização se desencadeia na maioria das cidades brasileiras não está dissociada do que acontece com a cidade de Salvador. Verifica-se elevada dificuldades de promoção da melhoria das condições de vida da maioria da população. Há intensa concentração, variando desde o adensamento populacional em determinadas áreas, em detrimento de outras, passando pelo acesso à renda até as condições dignas de moradia. A necessidade de implementação do processo de urbanização calcado nos vieses da democracia, buscando o difícil mas não impossível exercício da participação torna cada vez mais eminente, para combater os riscos estudados e a consequente erradicação da pobreza.

Nota-se que algumas intervenções têm sido feitas pelos órgãos federais, estaduais e municipais, a exemplo das obras de contenção de encostas, porém com maior concentração nas áreas mais nobres e com sérias dificuldades de acesso às populações carentes. $\mathrm{Na}$ realidade, a ocupação da cidade de Salvador está predominantemente localizada nas áreas de encosta. Entretanto, a população mais abastada geralmente está mais bem provida de recursos tecnicos, principalmente com o aporte de profissionais qualificados, a exemplo dos engenheiros e arquitetos, o que inibe a ocorrência de riscos ambientais. Enquanto isso, a população de baixo poder aquisitivo não dispõe desses recursos, além da carência de serviços básicos de educação, saúde e saneamento básico, o que concorre para a intensificação dessa problemática ambiental.

Assim, a análise de riscos ambientais tem uma abordagem complexa, o que exige a realização de 
trabalhos multidisciplinares. A aproximação dos órgãos públicos com os setores organizados da sociedade civil e, principalmente, com os pesquisadores das universidades que desenvolvem estudos sobre esta questão se apresenta como importante perspectiva de busca de alternativas para os riscos ambientais. A realização deste trabalho, apresentado no II Congresso Internacional de Riscos, realizado na cidade de Coimbra, visa aproximar as discussões que possam contribuir para a melhoria das condições de vida dos habitantes das áreas urbanas .

\section{Referências bibliográficas}

ANDRADE, Adriano Bittencourt (2004) A cidade de Salvador, dos idos de 1959: os olhares de Jorge Amado e Milton Santos. In Pinheiro, Délio José Ferraz \& SILVA, Maria Auxiliadora da, Visões Imaginárias da cidade da Bahia, EDUFBA, Salvador-Bahia, p. 31-48.

BeCK, Urich (1992) Risk Society, SAGE publications, London.

TelxeIra, Antonio José \& Cunha, Sandra Baptista, orgs (2000) Impactos Ambientais Urbanos no Brasil. Editora Brasil, São Paulo, p. 19 - 45.

GonçAlves, Neyde Maria Santos (2003) Impactos pluviais e desorganização do espaço urbano em Salvador, In Monteiro, Carlos Augusto Figueiredo \& Mendonça, Francisco Clima Urbano, Contexto, São paulo, p 69-91.
GuerRA, Antonio José Teixeira \& CunHA, Sandra Baptista da (2001) Impactos ambientais urbanos no Brasil, Editora Bertrand, Rio de Janeiro.

Lamas, José M. R. Garcia (2000) - Morfologia urbana e desenho da cidade, Fundação Calouste Gulbenkian, Lisboa.

Matroso, Kátia M. de Queirós(1992) Bahia século XIX uma província no império. Nova Fronteira, Rio de Janeiro.

PREFEITURA MUNICIPAL DE SALVADOR (2003) Relatório do inventário das áreas de riscos, PMS, SEMIN, Salvador.

Monteiro, Carlos Augusto (2008) Geografia sempre: o homem e seus mundos. Territorial, São Paulo.

Rebelo, Fernando (2003) Riscos Naturais e Acção Antrópica:estudos e reflexões, $2^{\mathrm{a}}$ edição, Imprensa da Universidade, Coimbra.

SAntos, Miguel Cerqueira \& GóIS Djalma Villa (2004) Urbanização e riscos ambientais no Recôncavo Baiano. In Revista territorium, 11, Associação Portuguesa de Risco, Coimbra, p.15 - 20.

SAntos, Milton (1958) A rede urbana do Recôncavo. UFBA, Salvador.

Santos, Milton (1979). O espaço dividido: os dois circuitos da economia urbana dos países subdesenvolvdos. F. Alves, Rio de Janeiro. 